\title{
Grundtvig-manuskripter og grundtvigiana i Det kgl. Bibliotek erhvervet I 963 - maj 1972
}

\author{
Ved Steen Fohansen
}

Tilstrømningen af Grundtvig-manuskripter (samt papirer m. v., der berører Grundtvig og hans kreds) til Det kgl. Bibliotek fortsætter stadig, tilsyneladende uden tegn på ophør. I ı 957-64 udkom »Grundtvig-Registranten«, hvori udførligt var nævnt og fortegnet de i biblioteket kendte og værende Gr.-mss. til og med ca. 1963. Siden da er gået næsten 10 år, i hvilke nye Gr.-mss. stadig er indgået, så mange, at en fortegnelse længe har været følt nødvendig. Den følger hermed, ført op til og med maj 1972.

Med begrebet »Grundtvig-manuskript« forstås ikke uden videre en ny, hidtil ukendt tekst af Gr. Flertallet af erhvervelserne har, som man vil se af fortegnelsen, været kendt og også trykt tidligere. Men ind imellem vil man også kunne finde adskillige nye og forhåbentlig interessante ting. Som prøver aftrykkes efter fortegnelsen tre hidtil ukendte breve fra Grundtvig.

Forkortelser anvendt $i$ det følgende:

Breve I-II $=$ den af Georg Christensen og Stener Grundtvig udgivne samling »Breve fra og til N. F. S. Grundtvig«. I-II (1924-26).

Fotostaterede en samling fotokopier af breve, hørende til bibliotekets håndbreve $=\quad$ skriftsamling.

Gr. $=\quad$ N.F. S. Grundtvig.

Gr.-bibl. $=$ Steen Johansen: Bibliografi over N.F.S. Grundtvigs skrifter. I-IV ( $1948-54$ ).

Gr.-reg. = Registrant over N. F. S. Grundtvigs papirer. I-XXX (1957-64).

N.B.D. 2. rk. $=$ Nyere brevsamling. Dansk. 2. række. En af håndskriftsamlingens brevsamlinger.

$\mathrm{NkS}=\quad$ Ny kongelig Samling.

PS $=\quad$ N.F.S. Grundtvigs Poetiske Skrifter. I-IX (1880-1929).

Troensegård $=$ Grundtvigsmanuskripterne $\mathrm{i}$ skovejer $T$. Troensegårds store autografsamling, som Det kgl. Bibliotek erhvervede i 1970. 
Bemark:

Under signaturen NkS $4680,4^{\circ}$ skjuler sig en af landsretssagfører Mogens Müllertz til biblioteket i 1968 skænket større samling mss. af og vedr. Grundtvig.

Nedenstående fortegnelse medtager også ganske få Gr.-papirer og grundtvigiana, som fandtes i bibliotekets håndskriftsamlinger før i 963 , men som først er blevet opdaget efter dette tidspunkt.

\section{PERSONALIA}

»Stamtavler over slægten Grundtvig «.

Udgør I) let ændret dublet af den af Gr.s fader pastor Johan

$\mathrm{NkS} 256 \mathrm{I}$, fol.

Gr. udarbejdede stamtavle over Gr.-slægten, hvis andet eks. allerede findes i biblioteket ( $\mathrm{NkS} 2493,4^{\circ}$, se Gr.-reg. XXVI, m. nærmere oplysninger). 2) Forskellige stamtavler over (grene af) den norske slægt Stenersen, som Gr.s ældste søn Johan giftede sig ind i i 1855 .

En af Gr.s farbroder, sognepræst i Holbæk og Udby, Hans forgen $G r$. underskrevet erklæring vedr. hans kones slægtning, Kathrine Raupach.

\section{II}

\section{BREVE}

I. Breve fra N.F.S. Grundtvig

Gr. til Chr. Bayer 30/12 I867.

Tryk: Chr. Bayer: Gamle Minder. (1925).96. Nederst på brevet har C. B. noteret: Disse linier modtog jeg af Biskop Grundtvig i hans Bolig paa Strandveien den 3ote Decbr. I867. C. Bayer.

Gr. til Franciska Carlsen 6/6 1857 .

Hidtil utrykt.

Gr. til Direktionen for Fattigvasenet i Kbh. I4/6 I849. Hidtil utrykt.

Fr. til Forlagsbureauet. Udateret.

Hidtil utrykt.

Gr. til fru Marie Glahn I6/9 I8I9.

Tryk: Breve I nr. 193.

Gr. til Lise Gr. I/5 I82 I.

Tryk: Breve II nr. 238.

Gr. til Fr. Hammerich 8/5 I84I.

Tryk: Breve II nr. 44I.

Troensegård

do.

N.B.D. 2. rk.

$\operatorname{NkS} 2632,4^{\circ} \cdot I^{a}$

Troensegård

Fotostaterede

breve

Troensegård 
Gr. til Abraham Kall 10/8 I8og.

Fotostaterede

Tryk: Breve I nr. 6. - Orig. ejes af afdelingsingeniør P. breve

Vedel.

Gr. til Chr. Molbech 5/I I8I I.

Tryk: Molbech-Gr.s brevveksling ( 1888 ), 55 .

Gr. til Peter Rørdam 31/ro I848.

Tryk: Breve II nr. 569 .

Gr. til Anna Pouline Schmidt, f. Blicher, 24/10 I8I 2.

Hidtil utrykt.

Gr. til F. F. Schouw 6/1 1826 .

Hidtil utrykt. Er et svar på Breve II nr. 293 (fra Schouw til Gr.).

Gr. til Vilhelmine Stenersen 20/ I 1855.

Tryk: Breve II nr. 634 .

Gr. til $C$. $A$. Winther $5 /$ I I 1847 .

Tryk: Breve II nr. 546 .

Gr. til (en frue) 24/9 1857.

Hidtil utrykt. Adressaten indtil videre usikker.

Ms. til et tidligere trykt brev fra Gr. til Studenterforeningen i 1845 (se Gr.bibl. nr. 835 d) findes i Studenterforeningens Arkiv i Det kgl. Bibliotek.

\section{Breve til N.F.S. Grundtvig}

Fohan Andreasen til Gr. 25/1 2 I869.

Utrykt.

Troensegård

$\mathrm{NkS}$

2659 , fol.

Troensegård

do.

N.B.D. 2. rk.

Troensegård

$\mathrm{NkS}_{4680,4^{\circ}}$

\section{Andre breve}

Gunni Busck til Asta Gr. 25/7 1867.

Utrykt.

Fohan Gr. (Gr.s fader) til Fritz v. Raben $2 / 8$ I 788 .

(Vedr. det da ledige skoleholderembede i Udby).

Utrykt.

Oline Olsen til Asta Gr., udat.

Utrykt.

Fohs. Schroder til Asta Gr. 22/7 1874.

Utrykt.

Maja Weis til Asta Gr. (Gr.s datter) 4/9 I88I.

Utrykt.

do.

»Brevveksling mellem Johan Gr. og hans moder 1848-50«.

Denne samling var uomtalt i Gr.-reg., fordi dengang skønnet noget uvedkommende. Udvalg heraf er trykt i Ingeborg Simesen: N. F. S. Grundtvig og hans nærmeste Slægt under Treaarskrigen. (1933).

do.

Troensegård

$\mathrm{NkS} 4680,4^{\circ}$

do.

do.

$\mathrm{NkS}_{3650,4^{\circ}}$ 


\section{DIGTE}

»Alting under Solen ældes«. (7 vers).

$\mathrm{NkS} 4680,4^{\circ}$

Titel: Dronningens Aarsdag 28de Juni 1858.)

Tryk: PS VIII 292-294.

»Asta! naar vi med Guds Naade«. (Rim).

do.

Titel: Til min Asta! (Aarsdagen I2te Marts 1858.)

Tryk: PS VIII 28 if.

»Da Fuglene alle med Vinger«. (6 vers)

do.

Titel: Til min Maries Datter. (Årsdagen 1859.$)$

Tryk: PS VIII 3 io $\mathrm{f}$.

»Danne-Brog og Gylden-Løve «. (5 vers)

Titel: Til Hs. Excellence Grev G. C. S. Danneskjold-Samsøe paa Gisselfeld. - Ms. er en afskrift (afskriver unævnt).

Tryk: PS V 50-52.

»De første syv er Legens Aar《. (7 vers).

Titel: Til Frederik min yngste Søn fra 15 Mai 1854 .

Tryk: PS VIII 472-474. - Ms. dateret I5/5 I86I.

»Der flyver en Fugl over Skov og Sø«. (5 Vers).

Titel: Til Dronningen (Aarsdagen 1859).

Tryk: PS VIII $3 \mathrm{I} 4 \mathrm{f}$.

»Der gik en yndig Tone «. (7 vers)

Titel: Svenn og Laura Brudefolk Iode Decbr 1858 .

Tryk: PS VIII $300 \mathrm{f}$.

»Det var Fjeldene ei blot«. (9 vers).

Titel: Den gamle Skjald (N. F. S. Grundtvig).

Tryk: PS VIII 286-288.

»Ei jeg paa din Aarsdag sang«. (Rim).

Troensegård

Titel: Til Asta, Marie, Elisabet Grundtvig.

Tryk: Gr-Studier 195I, 53 f. (hvor dog et andet ms. er fulgt).

$\gg$ En er forud for sin Alder«. (Rim).

Titel: Til min yngste Sons Frederik Lange Grundtvigs

$\mathrm{NkS} 3882,4^{\circ}$

Aarsdag 1867. Mai 15.

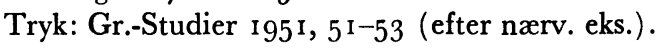

»En er forud for sin Alder«. (Rim).

$\mathrm{NkS}{ }_{3} 882,4^{\circ}$

$\mathrm{NkS} 4680,4^{\circ}$

do.

do.

do.

Titel den samme som foregående. - Vi har altså, som undertiden, to af $\mathrm{Gr}$. nedskrevne eks. af samme digt.

»Guds Menighed er en Eva ny«. (12 vers).

do.

Titel: Herrens Brud. (N. F. S. Grundtvig).

Tryk: Gr.: Sang-Værk V (1951), nr. I I3.

»I Medgang og Modgang«. (6 vers).

do.

Titel: Astas Aarsdag (12te Marts I864).

Tryk: PS IX $76 \mathrm{f}$. 
»Indtil hvad vi Skiels-Aar kalder«. ( 23 vers).

$\mathrm{NkS}_{3882,4^{\circ}}$

Titel: Til min yngste Søn Frederik Lange.

Tryk: PS IX 278-282. - Ms. er dateret: I5/5 1866.

»Indtil hvad vi Skiels-Aar kalder《. ( 22 vers).

Titel: I866. Mai I5. Til F. L. Grundtvig.

Tryk: se forrige digt.

»Ingen Sanger trindt om Land«. ( I 7 vers).

Titel: Skjalde-Lønnen. (N. F. S. Grundtvig).

Tryk: PS VIII $283 \mathrm{f}$.

»Jeg gik mig ud i Lunden«. (9 vers).

Titel: Til fette og Marie (Mai I837.)

Tryk: PS VI i68-i 70.

»fesus! Du paa Bjergets Tinde«. (3 vers).

Titel: Brødet i Ørken. I øverste venstre hjørne: I867.

Hidtil utrykt.

»fesus, Dødens Overvinder!« ( I 8 vers).

Titel: Ordets Opstandelse.

Tryk: Nord. Kirketidende I7/8 i 834 .

Nærv. ms. er tryk-ms.

»Kiærlighed slog op sit Øie«. ( 7 vers + et overstreget vers).

Titel: Kiærligheden. - I øverste venstre hjørne: 1867.

Hidtil utrykt. - Er skrevet på samme læg som ovenanførte digt $\gg$ Jesus! Du paa Bjergets Tinde«.

»Kongen sagde: syg er jeg« og »Alle Verdens Riger ældes«.

Med fællesoverskriften »Ved Takkebønnen for H. M. Kon-

gens Helbredelse« tryktes disse to digte i $185^{8}$.

»Kun en Guds Engel«. (7 vers).

Titel: Til min fru Asta! (mens Pennen endnu skælvede).

Tryk: PS IX 270 f. - Tidligere trykt i i8gi.

$»$ Længe leve i Danevang ..«( I vers).

Undertegnet: N. F. S. Grundtvig.

Dette vers, egenhændigt skrevet af Gr. på særskilt stykke papir, findes indklæbet i H. C. Andersens berømte »Stambog« i Det kgl. Bibliotek. Udgør sidste vers af »Moders Navn er en himmelsk Lyd « $i$ dette digts orig.form fra 1838 . (Dog med en variant i lin. 3: »Op da stander i Pigesang«, hvor 1838 -teksten har: »Op det stande ...«).

» Paa min Aarsdag her i Nord «. (3 vers).

Titel: Til Asta. (8. Septbr I858).

Tryk: PS VIII 299.

»Paaskemorgen Magdalene«. ( 2 vers).

$\mathrm{NkS}_{3882,4^{\circ}}$

do.

do.

$\mathrm{NkS}_{4} 680,4^{\circ}$

do.

do.

do.

$\mathrm{NkS}{ }_{4680,4^{\circ}}$

Titel: Marie Magdalene.

Tryk: Dansk Kirketidende 4/4 1847.

»Sagt det er med Ord fuldrene«. ( I 4 vers).

Afskrift. - Titel: Det kristelige Ægteskab.

do.

Hidtil utrykt. (Orig.-ms. findes i Gr.arkivet).

Troensegård

$\mathrm{NkS}_{4680,4^{\circ}}$ 
»Skarpsindighed er Tydskens Brodd «.

do.

Versantal uklart; kladde eller udkast.

Trykt 187i. - PS IX 6i $6 \mathrm{f}$.

»Svend Grathe var Konning i Danmark«. ( I I vers).

Troensegård

Ingen titel. - Enkelttryk I840.

PS VI 289-292.

»Syv Gange ti er Støvets Aar«. (4 vers).

Titel: Til Frederik Lange Grundtvig, min yngste Søn (paa

hans rode Aarsdag I5de Mai I864).

Tryk: PS IX $79 \mathrm{f}$.

»Tak for alle Aarets Dage«. (5 vers).

Titel: Til Asta-Moder ( 1867. Marts 12.)

Tryk: PS IX 29I-293.

»Tallet »Syv« fra gamle Dage«. ( 7 vers).

Titel: Til Asta-Moderen, Fru Asta ( 1865. Marts I2.)

Tryk: PS IX $268 \mathrm{f}$.

»Til Verden jeg kom i Bøgely«. ( 7 vers).

$\mathrm{NkS}_{3882,4^{\circ}}$

Titel: Til Fru Asta! (8 Septbr I86o.)

Tryk: PS VIII $466 \mathrm{f}$.

»Tre er alle gode Gange«. (5 vers).

Til: Til Fru Asta! (186r. April 16)

Tryk: PS VIII 47i f.

»Tunge Dage, Nætter lange«. (9 vers).

$\mathrm{NkS}_{4} 68 \mathrm{o}, 4^{\circ}$

Titel: Til Fru Asta! ( 2 Marts I86I.)

Tryk: PS VIII 468-470.

»Underligt er vort jævne Land«. (6 vers).

Titel: Til min Asta! (N. F. S. Grundtvig).

Tryk PS VIII $294 \mathrm{f}$.

»Velkommen her ved Leiregaard «. (9 vers).

Ingen titel. - Trykt første gang I86r.

PS VIII 476-478.

»Verdens Haab er vel beskrevet«. (5 vers).

Titel: :Til Asta! (Aarsdagen I 2te Marts I859.)

Tryk: PS VIII $309 \mathrm{f}$.

»Vinde og tabe er Kiøbmands-Brug«. ( 12 vers).

Titel: Perlen.

Tryk: Dansk Kirketidende I I/5 I856.

»Vær hilset, Norges Klippeland «. (5 vers).

Ingen titel. - Enkelttryk 1851 .

PS VII 44If.

»Ønsker, Lille! du at leve«. ( 2 vers).

Titel: Livets Ord (N. F. S. Grundtvig).

Tryk: Gr.: Sang-Værk V ( I95 I), nr. 229.

»Øresund ved Axelstad«. (20 vers).

do.

do.

do.

do.

do.

do.

do.

Troensegård

Titel: Øre-Sundet.

Tryk: PS VIII 302-308. 
Forarbejder til »Den levende Røst« ( 1863 ).

do.

Udgør en række oktavlæg (ialt 69 blade) med udkast, kladder olgn. til nævnte større kvad af Gr., udgivet særskilt ı863. Sammen med andre bevarede mss. har pastor Uffe Hansen benyttet disse til sin udgivelse af kvadet $\mathrm{i}$ femte bind af sin Sang-Værk-udgave (I95I), se herom notebindet (VI) til nævnte udgave side $445 \mathrm{ff}$. (Uffe Hansen har således haft adgang til disse mss., før de skænkedes til Det kgl. Bibliotek).

\section{Afskriftsamlinger}

Afskrifter (ved Asta Gr.) af 2 I tidligere trykte digte af $\mathrm{Gr}$. do. (samt af 5 til disse knyttede korte taler af $\mathrm{Gr}$.), alle fra tiden $1838-65$.

Afskrifter (ved Johs. Schrøder) af 40 tidligere trykte digte do. af Gr., fra tiden I808-70. Var bestemt til Asta Gr.

\section{IV}

AFHANDLINGER, ARTIKLER ETC.

Er Troen virkelig en Skole-Sag?

Troensegård

Tryk-ms. til artikel i Nord. Kirketidende 31/I 1830.

Hvad kommer det Præsten i Vartov ved, at Præsten i Ryslinge

bliver afsat?

Tryk-ms. til artikel i Dansk Kirketidende I/ Io I865.

Tale af Gr. på Store Tuborg 8/9 187 I.

Afskrift (et oktavlæg).

Tryk, se Gr.bibl. nr. $1_{4} 6_{5}$ a.

PRÆDIKENER, KIRKELIGE LEJLIGHEDSTALER ETC.

Ved Fru Skibsteds Baare. (26. Aug 1859.)

Troensegård

Tekst på et kvartlægs alle 4 sider.

Tryk: Gr.: Kirkelige Leilighedstaler. (1877), I 40 f.

Afskrift (ved fru Asta Gr.) af prædiken af Gr. 14/4 1867. $2 \quad \mathrm{NkS} 4680,4^{\circ}$ oktavlæg, titel: Palme-Søndag.

Onsdag I 7 de April 1867. Melding.

do.

Orig.-ms. - Hidtil utrykt, men benyttet af Gr.-forskningen.

Langfredag I867. Verbal-Note.

Afskrift (ved fru Asta Gr.). - Som forrige.

Afskrift af prædiken af Gr., 2 oktavlæg.

På ms. er noteret: Dette efter Grundtvigs egen mundtlige

$\mathrm{NkS}_{4} 680,4^{\circ}$

do.

diktat - Onsdag eftermid: d. I 7 de Juli 1872. 
Orig.-ms. af Gr. til udateret prædiken. Tekst på begge sider af et kvartblad. Det er foreløbig uvist, om nærv. ms. udgør hele prædikenen. - Vist fra 1850 'rne.

Afskrift af I I9 prædikener af Gr. I858-7I.

Disse afskrifter (ved frk. Caroline Munthe af Morgenstierne) er foretaget for enkedronning Caroline Amalie.

Nedskrift (ved Asta Gr.) af Gr.s kirkebøn i Vartov.

Ingen titel; 2 oktavlæg. - Vist utrykt.

\section{$\mathrm{VI}$}

\section{MINDRE OPTEGNELSER}

Et bevaret for- og bagomslag af et optegnelseshæfte (i oktav), findes i A. Fibigers autografsamling. På foromslagets første side er (ikke af Gr.) skrevet: Homers Ilias. På sammes anden side har Gr. i 1798 skrevet følgende:

Hunc librum Meus frater Nicolaus Cristianus Bang Grundtvig Studiosus s. s. Theologiæ mihi dono dedit.

\section{N. F. S. Grundtvig.}

In Ædibus pastoralibus Udbyensis prope Ortungani Sællandiæ. XI Calendarum Nov:

Anno MDCGXCVIII.

Optegnelse af Gr. fra 1803 på første $I^{1 / 2}$ side af et oktavlæg, overskrift: Anmærkninger til min Komedie Brevet. - (Nævnte komedie skrev Gr. i tiden dec. I802-juli 1803 ).

Optegnelse (på et oktavblad) om Tyge Rothe. Aftrykt i H. Toldberg: Gr. som filolog. (I 946 ), 39 .

Smal, fraklippet strimmel $\mathrm{m}$. flg. håndskrevne tekst af $\mathrm{Gr}$.: Interessentskabet tiltræder jeg med Fornøielse og mine Erindringer ved Udkastet til Planen skal jeg med det Første fremsende. Udbye rode Septbr. I8I I. N. F. S. Grundtvig. Forklaring foreløbig usikker. Kan muligvis være Gr.s første tilsagn om at bistå ved en påtænkt oversættelse af Snorres kongesagaer, jf. Gr.-Studier I958, 55 f.

Sprogoptegnelse med overskriften: Frisisk. Udgør et oktavlæg ( 2 blanke sider af et brev, jf. ndf.) m. en liste over frisiske ord $\mathrm{m}$. da. oversættelse vedføjet. På samme læg et lille brev (udat.) fra chargé d'affaires P. Browne til Gr. - Vist fra I83o'rne.

Et oktavlæg, på hvis første $2^{1 / 2}$ side Gr. har skrevet øverst: Reliques of ancient english poetry by Thomas Percy V.I. (V.=Volume). The ancient ballad owt of chevy-chase. $»$ The Persé owt of Northomberlande«. (4 linier). På lign. måde har Gr. fortsat med at notere titlerne på (samt nedskrive de 4 første linier af) de første i I folkeviser i næunte bd. I af Percys Reliques. (Udgave anføres ikke). - Antagelig fra Englandsrejsernes tid.

$\mathrm{NkS}{ }_{26} 67$, fol.

Troensegård

do.

$\operatorname{NkS} 2453,4^{\circ}$

Troensegård

NkS $2453,4^{\circ}$ 


\section{GRUNDTVIGIANA}

Optegnelsesbog af pastor Johan Gr., hvori er nedskrevet skriftsteder til benyttelse ved kirkelige handlinger (begravelser, nadver, vielser osv.). I i8 I overtog Gr. bogen, hvorom han p. 57 noterer: Disse Texter ere samlede af min Fader Johan $i$ hans første Præsteaar: 1760 og efter 50 Aars Brug mig overantvordede til fortsat Anvendelse. Udby d: 9de Juli I8I I. N. F. S. Grundtvig. - Gr. har iøvrigt flere steder (p. 22, 38, 44, 54 og måske også andre steder) noteret forskelligt. - Gr. gav senere bogen til Peter Rørdam, efter hvis død den gik over til Frederik Lange Gr.

Optegnelse af pastor Johan Gr., dateret Udby 26/ I 1807.

fraklippet strimmel. Dateret I/I og 30/7 1807.

Optegnelse af pastor Johan Gr., dateret Udby 26/1 1807 .

En af Svend Gr. opsat liste (et kvartlæg) over bøger af Gr., afleveret til boghandler C. G. Iversen til opbevaring og forhandling. Dateret I/10 1856 .

Frederik Lange Grundtvig: Vers til Fader. 1871. - Udgør et i rødt skindbind indbundet hæfte $\mathrm{m}$. et håndskrevet digt af Fr. L. Gr. Udenpå bindet flg. datering i guldtryk: D. 8. Septbr. 1871. Teksten $=$ et af den 17-årige Fr. L. Gr. affattet lykønskningsdigt til sin fader på dennes 88-årige fødselsdag.

J. Aarsbo: Grundtvigs Sangværk til den danske Kirke. Skildringer fra den danske Kirkesangs Historie. I-II. 1940. Dette maskinskrevne ms. (i alt 587 kvartsider) er forf. af stadsbibliotekar J. J. Aarsbo (1878-1944), hvis interesse for det $i$ titlen angivne emne var kendt af flere. Er en populært formet skildring af dansk salmesangs historie, centreret om Gr.s salmedigtning.

Trykt skrivelse (kvartblad) med 28 håndskrevne underskrifter til kongen 1848 med bøn om at få Gr. til kongevalgt medlem af den grundlovgivende rigsforsamling.

Digt af Fr. Lange Gr., begyndende: 》Søde Asta med Øine blaa《 (3 vers). Titel: Til Astas Aarsdag den iode Februar 1864. Undertegnet: Fra Frederik. Med Asta menes Fr. L. Gr.s lille halvsøster, som nævnte dato fyldte 4 år. Fr. L. Gr. var selv io år gammel!

Anonymt digt »til Fru Bispinde Grundtvig«. (Io vers). Dateret: $12 / 3$ I 864 .

NkS 2650 , fol.

Troensegård

do.

do.

$\mathrm{NkS} 3882,4^{\circ}$

$\mathrm{NkS} 4635,4^{\circ}$

$\mathrm{NkS} 4680,4^{\circ}$

do.

do. 


\section{TEKSTPRØVER}

Brev fra Gr. i hans forlovelsestid til sin forlovedes søster, fru Anna Pouline Schmidt, f. Blicher, i København.

Kære Veninde!

Udbye d. 24. Octbr I812.

Et Par Ord maa jeg i al Hast dog sende dig i Dag, for at takke dig og din Mand for al venskabelig Omhu, hvorpaa jeg i de sidst forløbne Dage modtog saamange Prøver, ogsaa for at melde min lykkelige Hjemkomst. Turen var lidt haard, da jeg i Regn maatte kiøre næsten hele Natten; men Broders Kavai stod sig mandhaftig, og uden alt videre Vanheld naaede jeg det kiære Udbye velbetids i Gaar Aftes.

I det jeg takker Gud for alle sine naadefulde Førelser og for det Held, der fulgte mig paa den ganske Reise, maa jeg bevæges end mere ved at se, hvor nødvendigt det var, at jeg kom hjem i Aftes. Her er Ligpræken i Dag og min gamle Fader, som havde besluttet at holde den, er saa mat og svag, at han neppe vilde udholdt Forretningen. Visselig, når vi barnlig lægge vor Villie i den himmelske Faders, og give Agt paa hvad der møder os, da ville vi, selv i hvad vi kalde daglige Hændelser opdage Hans kærlige Forsyns Spor, derved opvækkes til at prise Ham og gaa trygge gennem Livet, som de, der vide, at de i Jesu Kristo have en kærlig Fader foroven, der talte vore Hovedhaar og vil føre os gennem Glædens og Sorgens Vei hjem til vort Fædreneland.

Vil du sige til min Broder, at Doctor Clausen har været i Udbye, og sagt, at han vilde erkyndige sig om de præstelige Forretninger i Torkilstrup paa Søndag otte Dage, saa at Broder fra den Side kan være rolig, ifald det skulde være ham vanskeligt at komme hjem til Søndagen.

Da jeg skal op i Kirken, maa jeg slutte med de kærligste Hilsner til Moder og Sødskende paa begge Sider. Er du engang stemt dertil, kunde du jo nok skrive et Par Ord til Svogeren i Udbye som med broderlig Hengivenhed er

Din Ven Grundtvig.

Brev fra Gr. til F.F. Schouw ( 1 789-1852), den senere så berømte videnskabsmand og politiker, som i 1827 blev svoger til baron Henrik Stampe, Nysø.

Kiære Ven!

Christianshavn 6te Jan 1826 .

Kun med et Par Ord kan jeg besvare Deres forrige Brev, da Forretninger i Dag have optaget min Tid, og jeg dog vilde skrive saa meget mueligt til den ulykkelige Ven, hvis bestandig voxende Forvirring kun er altfor kiendelig præget paa de Blade, han sendte mig. Om det jeg har skrevet kan i denne Tilstand giøre mindste gavnligt Indtryk paa ham, maa Gud vide; men jeg vil bede Dem vælge et roligt eller dog mismodigt Øieblik til at give ham Brevet, da det ellers udentvivl ganske vilde forfeile sin Virkning; thi jeg har, efter Deres Raad og mit dermed stemmende Skiøn, talt haarde Ord, som i en brusende eller indbildsk Stemning maaskee kunde giøre megen Skade, og ganske 
lukke hans Øre for mig. - Vil Gud, skriver jeg igien i Morgen, hvordan veed jeg ikke, thi under saadanne Omstændigheder kan vi kun vide det vist, at vi, med Guds Hjelp, vilde giøre vort Bedste, naar vi kunde ramme det.

Baronessen sagde, at han higede efter at komme herind, Skade, for vore Øine, at det ei skedte, og har man stræbt at holde ham tilbage, da har man gjort Synd imod ham; thi Spiren til dette Daarskab laae alt i et Brev fra ham i Sommer, jeg troede at have været lykkelig nok til at kvæle den, og var han kommet herind af Lyst til at tale med mig, vilde det, efter al Rimelighed lykkedes.

Dog, hvad nytter det bagefter at tale om Sligt? lad mig endelig vide, med næste Post, hvordan det er blevet, og bland, saa godt De kan, Mildhed med Strænghed! Gud forbyde dog at det skulde gaae videre! Hils de Bedrøvede! Herren trøste Dem! vi kan ikke.

Note til ovenst. brev:

Din Ven Grundtvig.

Den ulykkelige ven, hvorom der tales, er baron Henrik Stampe (1794-1876), der fra ung af led af (uskadelige) anfald af sindsforvirring. Baronessen er hans hustru Christine Stampe, f. Dalgas. Ægteparret ejede og beboede Nyso.

Brev fra Gr. til forfatterinden og historikeren Franziska Carlsen ( $1817-76$ ), søster til Gr.s anden hustru, Marie Gr.

Kiære Frøken Fransisca!

Khvn 6te Juni i 857.

Baade skulde og vilde jeg jo strax efter Pindsedagene skrevet Dem til, at jeg paa først kommende Mandag, om Gud vil, agter mig til Rønnebæksholm med Følge efter kiærlig In[d]bydelse, men jeg stod op i Tirsdags Morgen, som halv drukken og halv død, og har siden havt hvad jeg kalder en Alderdoms-Uge, da man ikke godt kan beslutte sig til andet end at sove. $\mathrm{Da}$ jeg imidlertid ikke kunde faae Lov til det nær saa meget, som jeg vilde, og maatte igaar baade til Lyngby, hvorfra jeg kiærligst skal hilse, og ud i Tivoli til GrundlovsFest, uden at jeg derved er blevet mere kaput, saa drister jeg mig dog til Reisen. Frederik, som igaar og i overgaars i Brøndby og Lyngby har smagt Livet i det Grønne, er henrykt ved Tanken om daglig Fart giennem Have og Skov. Svenn agter nok sidst i næste Uge ogsaa at benytte sig af Deres giæstmilde Indbydelse, da hans Allerkiæreste saa med det samme vil indtræffe i Rønnebæk Præstegaard.

Det vil først være med Middags-Toget jeg vover at sætte mig i langsom Bevægelse.

Kiærligst til Moder og Haralde fra

Deres Ven

N. F. S. Grundtvig. 


\section{Af: Sang-Værk til den danske Kirke (1837)}

I.

Hil dig, Frelser og Forsoner!

Verden Dig med Torne kroner,

Du det seer, jeg har isinde

Rosen-Krands om Kors at vinde,

Giv dertil mig Mod og Held!

2.

For Dit Ansigt vil jeg træde, Thi jeg troer, Du er tilstæde; Jeg tilbeder Dig i Støvet, Fordi reen, som Guldet prøvet, Du er dog miskundelig!

3.

I Dit røde Hav jeg havner, Dine Fødder jeg omfavner, Thi ei stolt Du mig foragter, Mig fra Korsets Træ betragter Du med dyb Medlidenhed!

4 .

Ak, hvor fattig! ak hvor nøgen! Gruelig er med Dig Spøgen! Men jeg veed, for det at lide, Født Du blev ved Midnats-Tide, Selv Du valgde Korsets Skam!

5.

Hvad har Dig hos Gud bedrøvet? Og hvad elsked Du hos Støvet, At $\mathrm{Du}$ vilde Alt opgive, For at holde os ilive, Os Dig at meddele heel?

6.

Kiærligheden, Hjerte-Gløden, Stærkere var her end Døden, Heller giver Du end tager, Ene derfor Dig behager Korsets Død i vores Sted!
7.

Ak! nu føler jeg tilfulde

Hjertets Haardhed, Hjertets Kulde!

Hvad udsprang af disse Fjelde, Navnet værdt, til at giengælde

Frelser-Mand, din Kiærlighed?

8.

Dog jeg troer, af dine Vunder Væld udsprang til stort Vidunder, Mægtig til hver Steen at vælte, Til Iis-Bjerge selv at smelte, Til at tvætte Hjertet reent!

9.

Derfor beder jeg med Taarer:

Leed den ind i mine Aarer, Floden, som kan Klipper vælte, Floden, som kan Iis-Bjerg smelte, Som kan Blod-Skyld tvætte af!

Io.

Du, som har Dig selv mig givet, Lad i Dig mig elske Livet, Saa for Dig kun Hjertet banker, Saa kun Du i mine Tanker Er den dybe Sammenhæng!

I I.

Skiøndt jeg maa som Blomsten visne, Skiøndt min Haand og Barm maa isne, $\mathrm{Du}$, jeg troer, kan det saa mage, At jeg Døden ei skal smage, Du betalde Syndens Sold!

I 2.

Ja, jeg troer paa Korsets Gaade, Giør det, Frelser, af din Naade! Staae mig bi, naar Fienden frister! Ræk mig Haand, naar Øiet brister! Siig: vi gaae til $\mathrm{P}$ aradis! N.F.S. Grundtvig 